\title{
Effect of Photosynthetically Active Radiation (PAR) from LEDs on Growth and Development of Chrysanthemum morifolium Ramat. cv. Zembla
}

\author{
Sunil Kumar ${ }^{1 *}$, M.C. Singh ${ }^{1}$, Subedar $\operatorname{Yadav}^{1}$ and D.K. Sharma ${ }^{2}$ \\ ${ }^{1}$ Division of Floriculture and Landscape Architecture, IARI, New Delhi -110012, India \\ ${ }^{2}$ Centre for Environment Science and Climate Resilient Agriculture, IARI, \\ New Delhi -110012, India \\ *Corresponding author
}

\section{A B S T R A C T}

\section{Keywords}

Chrysanthemum, Light emitting

diodes (LEDs),

Photosynthtically

active radiation

(PAR),

Photoperiod, Long day (LD).

\section{Article Info}

Accepted:

04 July 2017

Available Online:

10 September 2017
The experiment was conducted to study the effect of photosynthetically active radiation (PAR) on growth and development of chrysanthemum using LEDs. The chrysanthemum cv. Zembla were exposed to different photoperiodic treatments of day length extension illuminating from photosynthtically active radiation from LEDs for $6,9,12,15$ days at $15 \mathrm{~h} /$ day in growth chamber except for control. Every batch after exposure at $6,9,12,15$ days under red/blue LEDs was transferred to the chamber with white LEDs. All the growth and physiological parameters (plant height, number of leaves, internode length, leaf chlorophyll, leaf area and net photosynthetic rate) differed significantly during different stages of growth and found that the increased in photoperiod by 15 days with long days from LEDs there was an increase in plant height $(43.05 \mathrm{~cm})$, inter nodal length $(2.60 \mathrm{~cm})$, number of leaves (24.50) and leaf area $\left(224.83 \mathrm{~cm}^{2}\right) \mathrm{cv}$. Zembla maximum (15 days) exposure in LEDs. Early flower response was noticed which was advanced by 7 days as compared with control. Bud and flower diameter $(5.78 \mathrm{~mm}$ and $80.74 \mathrm{~mm})$ were maximum. Fresh and dry weight in stems and flower were significant which might have contributed with increased total chlorophyll $\left(4.43 \mathrm{mg} \mathrm{g}^{-1} \mathrm{fw}\right)$ content as application of light emitting diodes (LEDs) might be resulted in long day effect without disturbing the required minimum dark period for flower induction.

\section{Introduction}

Chrysanthemum is the most important cut flower in India as well as globe. It is qualitative short day plants (SDP), hence, flower induction is primarily regulated by light duration (photoperiod). It flowers uniformly when critical day-length photoperiod is $\approx 13.5 \mathrm{~h}$ or less, but fails to flower under the longer critical photoperiods (McMahon, 1999). At northern latitudes, chrysanthemums are grown in greenhouses year-round. In terms of floriculture, photoperiod control should focus on minimizing the number of days to flower induction. In cut chrysanthemum production, artificially long days (LDs) are maintained routinely for 2-3 weeks before the onset of short day (SD), because of the required stem length specification (Hisamatsu et al., 2008). The importance of light quality for morphogenesis has been reported in many plant species. Plants sense light quality via photoreceptors categorized as phytochromes, 
cryptochromes and phototropins, and these photoreceptors are in charge of a wide spectrum of morphogenesis (Takemiya et al., 2005). Among them, phytochromes are red and far-red light-sensitive but cryptochromes and phototrophins absorb blue (B) light (Lin, 2000). Extended stem length has been shown to occur as a part of a phytochrome-mediated response (Patil et al., 2003). In contrast to phytochromes, ' $\mathrm{B}$ ' light relatedphotoreceptors have also been suggested to be involved in the flowering process (Fankhauser and Ulm, 2011). It has been previously reported that supplemental ' $B$ ' light induces the flowering response of chrysanthemum more than critical day-length (Jeong et al., 2012). Thus, it is likely that supplemental B lighting has important functions in the flowering process. The application of supplemental lighting also allows greenhouse crops to promote biomass accumulation by increasing photosynthetic carbon assimilation (Hao and Papadopoulos, 1999).Therefore, using a B light supplementation may be a useful practical technique for optimizing cut chrysanthemum cultivation. However, there is limited literature on the effects of supplemental B light on the stem elongation of cut chrysanthemum. Furthermore, since the effect of Blight in relation to photoperiod length remains unknown, more knowledge is required about this phenomenon. So, keeping above view in mind an experiment was carried out to analyze the influence of photosynthetically active radiation (PAR) on growth and development of chrysanthemum using light-emitting diodes (LEDs).

\section{Materials and Methods}

A cultivar "Zembla" was used in this experiment. Terminal cuttings of $5-6 \mathrm{~cm}$ length were taken from the mother plants of cv. Zembla and propagated as self-rooted plants in a plug (pro)- tray filled with soil less media (a mixture of coco-peat, vermiculite and perlite in a ratio 3:1:1). After 30 days attaining 5-7 leaves and transplanted in a 10 $\mathrm{cm}$ diameter (and $7.3 \mathrm{~cm}$ depth), UV stabilized plastic pot filled with a growing media composed of well-prepared mix of soil, vermi-compost, sand and organic leaf manure. 20 uniform sized plants were selected, transplanted, fertigated with $2 \mathrm{~g} / \mathrm{l}$ mixture of 19:19:19 NPK and Then kept for healing under greenhouse conditions with long days before being exposed to lighting treatments. The experiment was conducted based on completely randomized design (CRD).

The plants healed for 15 days were placed in the growth chamber for the experiment on chrysanthemum was carried out during February, 2015 to May, 2015 in a growth chamber in field laboratory of CPCT, IARI at New Delhi. Whereas, the light intensity was fixed by making two different LED panels, one white LEDs and in another a mixture of red and blue LEDs. To achieve an interception of light at $110-120 \mu \mathrm{mol} \mathrm{m} \mathrm{sec}^{-1}$ from $80 \%$ red $20 \%$ blue PAR distributed over the plants in uniformity inside the growth chamber. LEDs light exposure was given for 15 hours as log day (LD) treatment except for control. Every batch after exposure at 6, 9, 12, 15 days under red/blue LEDs was transferred to the chamber with white LEDs. The light intensity was measured every day and plants were re-positioned for an optimal irradiance available. Each growth chamber had constant lighting for $15 \mathrm{~h}$ as long day for entire 15 day period. After the completion of the all treatments, plants that were exposed shifted to the greenhouse, maintained with day temperature, $24^{\circ} \mathrm{C}$ and night temperature fixed at $16-18^{\circ} \mathrm{C}$.

Observations were recordedon plant height $(\mathrm{cm})$, stem diameter $(\mathrm{mm})$, total number of leaves, leaf area $\left(\mathrm{cm}^{2}\right)$, leaf fresh and dry weight, stem fresh and dry weight (electronic wastage and hot air oven), net photosynthetic 
rate, stomatal conductance and total chlorophyll were measured at $0,15,30$ and 45 days after planting and time taken for flower bud induction, bud diameter ( $\mathrm{mm})$, time taken for flower opening (day) and flower diameter $(\mathrm{mm})$, flower fresh and dry weight were taken at blooming time. Photosynthetic rate and stomatal conductance rate were measured $\left(4^{\text {th }}\right.$ leaf from the apical terminal) using an infrared gas analyzer (LI-COR, Biosciences, USA, Model LI 64000). The $\mathrm{CO}_{2}$ concentration of the air entering the leaf chamber was adjusted to $400 \mathrm{mmol}^{-1}$ by using a $\mathrm{CO}_{2}$ gas container, and leaf temperature was maintained at $22^{\circ} \mathrm{C}$. Total leaf area was measured by using leaf area meter, LI-COR (Model 3100). Chlorophyll content in the leaves was measured by DMSO method (Hiscox and Israelstam, 1979). The data were analyzed by using statistical package OPSTAT version.

\section{Results and Discussion}

The effect of long days through LEDs was pronounced on plant height and recorded maximum $(43.05 \mathrm{~cm})$ in the plants kept for 15 days measured at 45 days after planting. Whereas, plants kept under control (Long day exposure with white LEDs) could attain only $31.5 \mathrm{~cm}$ registered $36.66 \%$ increase due to longest (15 days) exposure under LEDs. However, the effect of different photoperiods from LEDs was significant and improved the stem thickness. Maximum stem diameter $(5.16 \mathrm{~mm})$ was recorded at 45 day after transplanting under 15 days exposure. However, an increase of $10.49 \%$ in stem diameter was estimated due to 15 day exposure over the control. Stem diameter increased with the plant growth and subsequently resulted in higher accumulation of dry matter in the plants. This is, because of more cell elongation, and increased internodal length and plant height. Since, chrysanthemum is an obligate short day plant, internal genetic behaviour of the plant hastens flowering without sufficient vegetative growth of plant in the absence of sufficient light. An experiment, application of different photoperiodic lengths on short day planted chrysanthemum has little influence of stem diameter as supported by the results achieved by Li et al., (2010) that the leaf attained more thickness under blue light in comparison with red light and different mixture of red and blue light in upland cotton. Kim et al., (2004) also found that different synergistic interaction between blue and red light receptors promote the stem elongation but its depending upon the nature of species.

The longest internodal length was measured at $45^{\text {th }}$ days after planting in the plants exposed with LEDs for 15 days $(2.60 \mathrm{~cm})$. However, the shortest internodes were recorded in the plants kept under control (2.05 $\mathrm{cm})$. Increase in plant height and stem elongation was resulted due to increase in length of internodes rather than number of internodes. Similar findings were reported by Appelgaren (1991) found significant differences recorded in internodes length but non-significant in internode number due to the effect of light quality. Similarly Kim et al., (2004) also reported that stem elongation in chrysanthemum was due to internodes length rather than their number and no effect of light quality in number of internodes was observed.

Maximum number of leaves (24.50) was recorded at 15 day exposure of LEDs followed by 12 days (23.50) and remains significantly higher than the recorded in the plants grown under control (19.75). On the other, maximum leaf area $\left(224.83 \mathrm{~cm}^{2}\right)$ was exhibited in the leaves of the plants exposed with long day LEDs for 15 day estimated 45 day after transplanting. However, plants without illumination with LEDs (control) had a lowest value $\left(196.18 \mathrm{~cm}^{2}\right)$. This might be 
due to enhanced biosynthesis of protein and carbohydrates leading to enhancement of initiation of leaf primordial growth under the influence of extended photoperiod and consequently production of more leaves. With the application of light treatment, the leaf area might have increased due to induced cell expansion as reported by Kim et al., (2004) that the leaf area was also greatest under FL and RB, while decreased mostly under BFr. Macedo et al., (2011) also found that the number of leaves/plant in Alternanthera brasiliana were significantly increased under blue fluorescent light as compared to with the other fluorescent- light and dark treatment.

The maximum leaves fresh weight was gained at 15 day $(8.64 \mathrm{~g})$ light treatment followed by $12(8.35 \mathrm{~g})$ and 9 days $(8.12 \mathrm{~g})$ days exposure and remained significant as compared with control $(6.43 \mathrm{~g})$.The dry weight of the leaves showed the similar trend for the treated plants and accumulated a highest dry weight (1.34g) in the plants exposed for 15 days exposure with LEDs followed by plants under 12 days (1.23g) harvested at 45 days as compared to the plants kept under the control $(0.90 \mathrm{~g})$. The maximum gain in fresh weight of stem (7.81 $\mathrm{g}$ ) in the plants treated with 15 days period as compared to the minimum $(5.25 \mathrm{~g})$ in the plants under control. Maximum dry weight accumulated in stems $(1.55 \mathrm{~g})$ in the plants exposed with 15 days as compared to lowest $(1.10 \mathrm{~g})$ in control. The increase in leaf weight of plants treated with light was due to the increase in leaf number as well as leaf size whereby more dry matter accumulated from the increased levels of photosynthetic pigment like chlorophyll and carotenoid. The findings of Menard et al., (2006), support this fact that the supplemental blue light increased plant dry weight of cucumber and tomato. Similarly Kim et al., (2004) found that the fresh weight, dry weight were also greatest under FL and $\mathrm{RB}$, while decreased the most under BFr. The data revealed that a maximum bud $(5.78 \mathrm{~mm})$ and flower diameter $(80.74 \mathrm{~mm})$ were recorded in 15 days long day exposed plants as compared to the minimum $(4.71 \mathrm{~mm}$ and $75.2 \mathrm{~mm}$, respectively) under control. It is evident from the data that an increase in day length exposure beyond 6 days to 15 days from LEDs, there was $22.71 \%$ increase in bud size over the diameter recorded in the treated plants over control. The flower harvested from the plants treated with long day LEDs exposure given for 6, 9 and 12 days was recorded $76.54 \mathrm{~mm}, 78.31 \mathrm{~mm}$ and 79.06 $\mathrm{mm}$, respectively which remained were at par with flower size attained at 15 days exposure to LEDs lighting (Table 1).

Flower bud initiation periods, however varied from 54 days in the plants exposed with longest duration (15 days) and had earliest appearance of flower bud as compared with control plants (61 days) which was delayed by 7 days. The plants treated with long day LED exposure for 6, 9 and 12 days had shown a significant early in flower bud induction by 1 , 4 and 6 days over the control. Time taken for flower opening varied significantly among the treated plants with long day exposure through LEDs as presented in table 2 and revealed that flower opening took maximum time was under control ( 70.75 days) followed by plants exposed for 6 days (70.50) and remained at par with each other. Whereas, 15 days long LEDs exposure could resulted in earliest (65.75 days) flower opening. Day length, if extended under natural available short day (SD) period, promotes vegetative growth and delays flowering. Bagnall et al., (1996) found that absorption of blue light accelerates flowering in Arabidopsis and Hyacyanus. Higuchi et al., (2012) reported that blue light plays an important role in the promotion of flowering under long day condition. Highest fresh and dry weights of flowers harvested from 15 days treated plants $(5.78 \mathrm{~g}$ and $0.79 \mathrm{~g}$, respectively). 
Table.1 Effect of photosynthetic active radiation (PAR) from LEDs on plant height, stem diameter, internodal length, number of leaves per stem and leaf area in Chrysanthemum morifolium cv. Zembla

\begin{tabular}{|c|c|c|c|c|c|c|c|c|c|c|c|c|c|c|c|c|c|c|c|c|}
\hline \multirow{3}{*}{ Treatment } & \multicolumn{4}{|c|}{ Plant height $(\mathrm{cm})$} & \multicolumn{4}{|c|}{ Stem diameter $(\mathrm{mm})$} & \multicolumn{4}{|c|}{ Internodal length $(\mathrm{cm})$} & \multicolumn{4}{|c|}{ Number of leaves/plant } & \multicolumn{4}{|c|}{ Leaf area $\left(\mathrm{cm}^{2}\right)$} \\
\hline & \multicolumn{4}{|c|}{ Day after planting } & \multicolumn{4}{|c|}{ Day after planting } & \multicolumn{4}{|c|}{ Day after planting } & \multicolumn{4}{|c|}{ Day after planting } & \multicolumn{4}{|c|}{ Day after planting } \\
\hline & 0 & 15 & 30 & 45 & 0 & 15 & 30 & 45 & 0 & 15 & 30 & 45 & 0 & 15 & 30 & 45 & 0 & 15 & 30 & 45 \\
\hline $\begin{array}{l}0 \text { day } \\
\text { (control) }\end{array}$ & .05 & 15.10 & 22.12 & 31.50 & 3.65 & 3.67 & 4.1 & 4 & 1.28 & 1.40 & 1.5 & 2.05 & 11 & 15.2 & ) & 19.75 & 10 & 0 & 174.45 & 196.18 \\
\hline 6 days & 05 & 15.50 & 2 & 7 & 3.49 & 3.89 & 4.17 & 4.86 & 1.35 & 1.48 & 1.70 & 2.13 & 10.75 & 00 & 25 & 20.50 & 105.19 & 154.73 & 180.08 & 201.35 \\
\hline 9 days & 11.05 & 17.00 & 25.95 & 36.60 & 3.66 & 3.96 & 4.44 & 4.89 & 1.28 & 1.55 & 1.63 & 2.15 & 10.25 & 17.25 & 19.25 & 20.25 & 101.17 & 162.85 & 184.30 & 205.15 \\
\hline 12 days & 11.05 & 17.57 & 27.37 & 42.02 & 3.74 & 4.09 & 4.55 & 5.13 & 1.33 & 1.60 & 1.83 & 2.38 & 10.75 & 17.25 & 19.50 & 23.50 & 100.97 & 168.10 & 188.90 & 216.78 \\
\hline 15 days & 11.07 & 19.00 & 28.8 & 43.05 & 3.63 & 4.14 & 5.01 & 5.16 & 1.40 & 1.85 & 2.05 & 2.60 & 11.00 & 18.00 & 20.00 & 24.50 & 100.15 & 176.08 & 197.35 & 224.83 \\
\hline C.D 0.05 & NS & 1.67 & 2.32 & 3.77 & NS & 0.24 & 0.24 & 0.24 & NS & 0.18 & 0.23 & 0.25 & NS & 1.37 & 1.64 & 1.86 & NS & 9.16 & 10.68 & 9.16 \\
\hline $\mathrm{SE}(\mathrm{m}) \pm$ & 0.29 & 0.55 & 0.76 & 1.24 & 0.13 & 0.07 & 0.08 & 0.08 & 0.06 & 0.06 & 0.07 & 0.08 & 0.41 & 0.45 & 0.54 & 0.61 & 1.81 & 3.01 & 3.51 & 3.01 \\
\hline
\end{tabular}

Table.2 Effect of photosynthetic active radiation (PAR) from LEDs on Leaves fresh, dry weight, stem fresh, dry weight, bud diameter, flower diameter, time taken for flower bud induction, flower opening, flower fresh and dry weight in Chrysanthemum morifolium cv. Zembla

\begin{tabular}{|c|c|c|c|c|c|c|c|c|c|c|c|c|c|c|c|c|c|c|c|c|c|c|}
\hline \multirow{3}{*}{ Treatment } & \multirow{2}{*}{\multicolumn{4}{|c|}{$\begin{array}{l}\text { Leaves fresh weight }(\mathrm{g}) \\
\text { Day after planting }\end{array}$}} & \multirow{2}{*}{\multicolumn{4}{|c|}{$\begin{array}{l}\text { Leaves dry weight }(\mathrm{g}) \\
\text { Day after planting }\end{array}$}} & \multirow{2}{*}{\multicolumn{4}{|c|}{$\begin{array}{l}\text { Stem fresh weight }(\mathrm{g}) \\
\text { Day after planting }\end{array}$}} & \multirow{2}{*}{\multicolumn{4}{|c|}{$\begin{array}{l}\text { Stem dry weight(g) } \\
\text { Day after planting }\end{array}$}} & \multirow{3}{*}{$\begin{array}{l}\text { Bud } \\
\text { diameter } \\
(\mathrm{mm})\end{array}$} & \multirow{3}{*}{$\begin{array}{l}\text { Flower } \\
\text { diameter } \\
(\mathrm{mm})\end{array}$} & \multirow{3}{*}{$\begin{array}{l}\text { Time } \\
\text { taken for } \\
\text { flower } \\
\text { bud } \\
\text { inductio } \\
\mathrm{n} \text { (day) }\end{array}$} & \multirow{3}{*}{$\begin{array}{l}\text { Time } \\
\text { taken } \\
\text { for } \\
\text { flower } \\
\text { openin } \\
\mathrm{g} \text { (day) }\end{array}$} & \multirow{3}{*}{$\begin{array}{l}\text { Flower } \\
\text { fresh } \\
\text { weight( } \\
\text { g) }\end{array}$} & \multirow{3}{*}{$\begin{array}{l}\text { Flowe } \\
\text { dry } \\
\text { weight }\end{array}$} \\
\hline & & & & & & & & & & & & & & & & & & & & & & \\
\hline & 0 & 15 & 30 & 45 & 0 & 15 & 30 & 45 & 0 & 15 & 30 & 45 & 0 & 15 & 30 & 45 & & & & & & \\
\hline $\begin{array}{l}0 \text { day } \\
\text { (control) }\end{array}$ & 3.61 & 4.22 & 4.68 & 6.43 & 0.39 & 0.62 & 0.71 & 0.90 & 1.56 & 3.29 & 3.86 & 5.25 & 0.26 & 0.58 & 0.80 & 1.10 & 4.71 & 75.20 & 61.25 & 70.75 & 4.71 & 0.61 \\
\hline 6 days & 3.66 & 6.06 & 6.79 & 7.36 & 0.42 & 0.79 & 0.99 & 1.06 & 1.71 & 3.36 & 4.21 & 5.95 & 0.29 & 0.62 & 0.84 & 1.24 & 4.81 & 76.54 & 60.50 & 70.50 & 4.81 & 0.60 \\
\hline 9 days & 3.73 & 6.05 & 7.33 & 8.12 & 0.41 & 0.80 & 1.07 & 1.24 & 1.77 & 3.44 & 4.36 & 6.18 & 0.28 & 0.64 & 0.89 & 1.27 & 5.06 & 78.31 & 57.75 & 68.50 & 5.06 & 0.70 \\
\hline 12 days & 3.63 & 6.26 & 7.32 & 8.35 & 0.40 & 0.83 & 1.08 & 1.23 & 1.60 & 3.49 & 5.52 & 6.61 & 0.26 & 0.64 & 1.12 & 1.34 & 5.62 & 79.06 & 55.75 & 67.00 & 5.62 & 0.79 \\
\hline 15 days & 3.61 & 6.77 & 7.83 & 8.64 & 0.38 & 0.87 & 1.27 & 1.34 & 1.60 & 3.54 & 5.95 & 7.81 & 0.29 & 0.67 & 1.21 & 1.55 & 5.78 & 80.74 & 54.00 & 65.75 & 5.78 & 0.79 \\
\hline C.D 0.05 & NS & 0.64 & 0.92 & 0.56 & NS & 0.06 & 0.19 & 0.11 & NS & NS & 0.68 & 0.52 & NS & NS & 0.14 & 0.10 & 0.24 & 2.11 & 1.32 & 0.92 & 0.24 & 0.05 \\
\hline $\mathrm{SE}(\mathrm{m}) \pm$ & 0.13 & 0.21 & 0.30 & 0.18 & 0.02 & 0.02 & 0.06 & 0.04 & 0.12 & 0.08 & 0.22 & 0.17 & 0.02 & 0.03 & 0.05 & 0.03 & 0.08 & 0.70 & 0.43 & 0.30 & 0.08 & 0.02 \\
\hline
\end{tabular}


Fig.1 Effect of photosynthetic active radiation (PAR) from LEDs on net photosynthetic rate in Chrysanthemum morifolium cv. Zembla

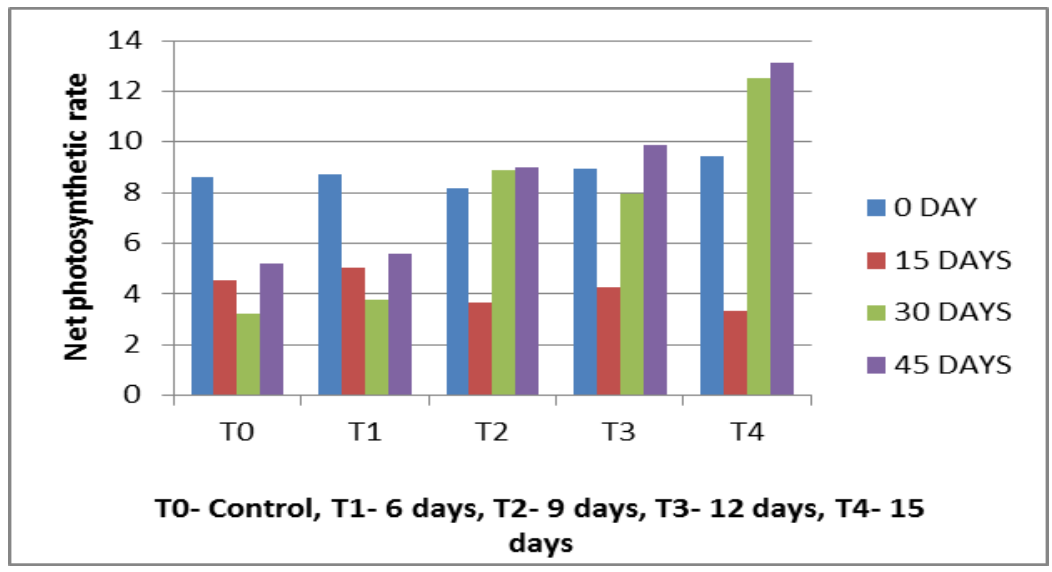

Fig.2 Effect of photosynthetic active radiation (PAR) from LEDs on stomatal conductance in Chrysanthemum morifolium cv. Zembla

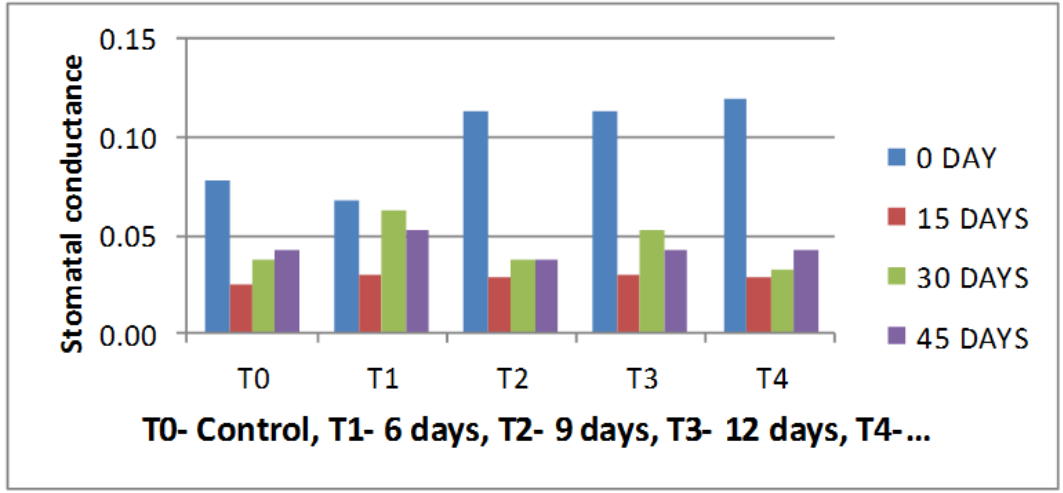

Fig.3 Effect of photosynthetic active radiation (PAR) from LEDs on total chlorophyll in Chrysanthemum morifolium cv. Zembla

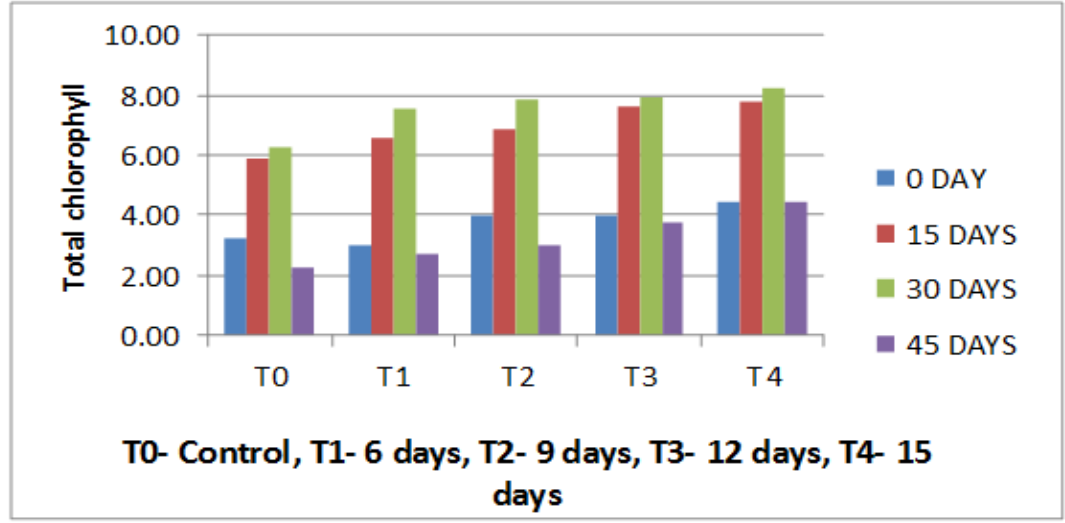


However the fresh weight differences were less pronounced in flowers from plants exposed under all four different length of exposures from LEDs. Dry weight of the flowers also showed an increased with increase in exposure duration and registered an increase $29.50 \%$ in the dry weight accumulated at 15 days long LEDs exposure as compared with flowers harvested from the plants under control $(0.61 \mathrm{~g})$.

The photosynthetic activity (Fig. 1) was found significantly higher in the leaves of plants kept under 15 days $\left(13.14 \mu\right.$ molm $\left.^{-2} \mathrm{~s}^{-1}\right)$ long day effect of LEDs measured 45 days after planting followed by the plants kept under 12 days long day treatment $\left(9.90 \mu \mathrm{molm}^{-2} \mathrm{~s}^{-1}\right)$ as compared with lowest in the plants under control (5.23 $\left.\mu \mathrm{molm}^{-2} \mathrm{~s}^{-1}\right)$. Stomatal conductance was recorded (Fig. 2) and showed a non-significant difference among the plants with and without long day exposure except for the plants provided with LEDs for 15 days and measured at $15\left(0.05 \mu \mathrm{molm}^{-2} \mathrm{~s}^{-1}\right)$ and $30(0.06)$ days after planting. Light quantity and quality has a profound effect on growth and flowering in chrysanthemum. Runkle and Heins (2006) were observed that plant receive more light so that the increase higher photosynthetic activity in plants. Kim et al., (2004) revealed that the net photosynthetic rate was highest under RB light followed by FL and lowest under BFr and B. Treated plants had more chlorophyll (4.43 $\mathrm{mg} \mathrm{g}^{-1}$ fw) measured in leaves exposed for 15 day long day exposure as compared with the leaves of untreated plants (control) and had a chlorophyll content of $2.22 \mathrm{mg} \mathrm{g}^{-1} \mathrm{fw}$ (Fig. 3). Whereas, plants grown under other exposures lengths of LEDs had increased values ranging from 3.04 $\mathrm{mg} \mathrm{g}^{-1} \mathrm{fw}$ at 9 days to $3.74 \mathrm{mg} \mathrm{g}^{-1} \mathrm{fw}$ at 12 days long exposure with LEDs. Blue light is very much important for chlorophyll formation, enzyme synthesis and photomorphogenesis as well (Menard et al., 2006). Whereas, Shin et al., (2008) reported that chlorophyll content was found to be highest in the plant grown under mixed blue plus red LEDs, followed by blue LEDs and florescent treatment and the red LEDs treatment showed remarkable reduction in chlorophyll content.
In conclusion, long days with $80 \%$ red $20 \%$ blue PAR from LEDs were found significant for plant height, inter nodal length, number of leaves and leaf area cv. Zembla at 15 days exposured in LEDs. Early flower response was noticed which was advanced by 7 days as compared with control. Bud and flower diameter were maximum. Fresh and dry weight in stems and flower were significant which might have contributed with increased total chlorophyll content as application of light emitting diodes (LEDs) might resulted in long day effect without disturbing the required minimum dark period for flower induction. The results of this study present a useful practical technique for cut chrysanthemum production in greenhouse horticulture.

\section{Acknowledgements}

This research was supported by Center for Protected Cultivation Technology, Division of Plant Physiology and Division of Floriculture and Landscaping, Indian Institute of Agricultural Research (IARI), New Delhi (India).

\section{References}

Appelgaren, M., 1991. Effects of light quality on stem elongation of pelargonium in vitro. Scientia Horticulturae 45 (3-4): 345-351.

Bagnall, D.J., 1996. Blue-light promotion of flowering is absent in hy4 mutants of Arabidopsis. Planta, 200, 278-280.

Fankhauser, C., and Ulm, R. 2011. Lightregulated interactions with SPA proteins underlie cryptochrome-mediated gene expression. Genes Dev., 25: 1004-1009.

Hao, X., and Papadopoulos, A. P. 1999. Effects of supplemental lighting and cover materials on growth, photosynthesis, biomass partitioning, early yield and quality of greenhouse cucumber. Scientia Hort., 80: 1-18.

Higuchi, Y., Sumitomo, K., Oda, A., Shimizu, H. and Hisamatsu, T. 2012. Day light 
quality affects the night-break response in the short-day plant chrysanthemum, suggesting differential phytochromemediated regulation of flowering. J. Plant Physiol. 169:1789-1796.

Hisamatsu, T., Sumimoto, K. and Shimizu, H. 2008. End-of day far-red treatment enhances responsiveness to giberellins and promotes stem extension in chrysanthemum. J. Hort. Sci. Biotech. 83: 695-700.

Hiscox, J.D., and Israelstam, G. F. 1979. A method for the extraction of chlorophyll from leaf tissue without maceration. Canadian Journal of Botany 57: 13321334.

Hogewoning, S.W., Trouwborst, G., Maljaars, H., Pooter, H., Van Leperen, W. and Harbin-son, J. 2010. Blue light doseresponses of leaf photosynthesis, morphology, and chemical composition of Cucumis sativus grown under different combinations of red and blue light. $J$. Exp. Bot. 61: 3107-3117.

Jeong, S. W., Park, S., Jin, J. S., Seo, O., Kim, G. S., Kim, Y. H., Bae, H., Lee, G., Kim, S. T., Lee, W. S. and Shin, S. C. 2012. Influences of four different light-emitting diode lights on flowering and polyphenol variations in the leaves of chrysanthemum. J. Agric. Food Chem. 60: 9793-9800.

Kim, S. J., Hahn, E. J., Heo, J. W. and Paek, K. Y. 2004. Effects of LEDs on net photosynthetic rate, growth and leaf stomata of chrysanthemum plantlets in vitro. Scientia Horticulturae 101 (1): 143151.

Li, H. M., Xu, Z. G. and Tang, C. M. 2010. Effect of light-emitting diodes on growth and morphogenesis of upland cotton (Gossypium hirsutum L.) plantlets in vitro. Plant Cell Tissue and Organ Culture 103 (2): 155-163.

Lin, C., 2000. Photoreceptors and regulation of flowering time. Plant Physiol. 123: 39-50.

Macedo, A. F., Leal-Costa, M. V., Tavares, E. S., Lage, C. L. S. and Esquibel, M. A. 2011. The effect of light quality on leaf production and development of in vitro cultured plants of Alternanthera brasiliana Kuntze. Environmental and Experimental Botany 70 (1): 43-50.

McMahon, M., 1999. Development of chrysanthemum meristems grown under far-red absorbing filters and long or short photoperiods. J. Amer. Soc. Hort. Sci. 124: 483-487.

Menard, C., Dorais, M., Hovi, T. and Gosselin, A. 2006. Developmental and physiological responses of tomato and cucumber to additional blue light. Acta Hort. 711: 291.

Patil, G.G., Oi, R., Gissinger, A. and Moe, R. 2003. Plant morphology is affected by light quality selective plastic films and alternating day and night temperature. Gartenbauwissenschaft. 66 (2): 53-60.

Runkle, E.S., and Heins, R. D. 2006. Manipulating the light environment to control flowering and morphogenesis of herbaceous plants. Acta Horticulturae. 711: 51

Shin, K.S., Murthy, H. N., Heo, J. W., Hahn, E. J. and Paek, K. Y. 2008. The effect of light quality on the growth and development of in vitro cultured Doritaenopsis plants. Acta Physiologiae Plantarum. 30 (3): 339-343.

Takemiya, A., Inoue, S. and Doi, M. 2005. Phototropins promote plant growth in response to blue light in low light environments. Plant cell.17: 1120-1127.

\section{How to cite this article:}

Sunil Kumar, M.C. Singh, Subedar Yadav and Sharma, D.K. 2017. Effect of Photosynthetically Active Radiation (PAR) from LEDs on Growth and Development of Chrysanthemum morifolium Ramat. cv. Zembla. Int.J.Curr.Microbiol.App.Sci. 6(9): 458-465. doi: https://doi.org/10.20546/ijcmas.2017.609.055 